\title{
Hubungan Fungsi Keluarga Dengan Kualitas Hidup Pasien Penyakit Kronis Degeneratif di Fasilitas Kesehatan Tingkat Pertama
}

\author{
Susi Oktowaty ${ }^{1}$, Elsa Pudji Setiawati², Nita Arisanti \\ ${ }^{1}$ Klinik Pratama Mitra Sehati \\ ${ }^{2}$ Departemen Ilmu Kesehatan Masyarakat, Fakultas Kedokteran Universitas Padjadjaran
}

\begin{abstract}
Abstrak
Fungsi keluarga merupakan salah satu faktor penting dalam mendukung peningkatan kualitas hidup pasien penyakit kronis. Memiliki kualitas hidup yang baik akan mengurangi risiko terjadinya komplikasi yang dapat memperburuk keadaan. Penelitian ini untuk mengetahui hubungan fungsi keluarga dengan kualitas hidup pasien penyakit kronis degeneratif yang tergabung dalam komunitas Program Pengelolaan Penyakit Kronis Badan Penyelenggara Jaminan Sosial Kesehatan atau Prolanis BPJS Kesehatan di Fasilitas Kesehatan Tingkat Pertama. Penelitian deskriptif analitik dengan pendekatan potong lintang ini dilakukan pada bulan Januari hingga Februari 2017 dengan menggunakan kuesioner dari WHO Quality of Life - BREF (WHOQOL-BREF) dan APGAR Keluarga. Teknik pengambilan sampel adalah total sampling sebanyak 128 peserta Prolanis di Klinik Pratama Mitra Sehati yang kontrol rutin dalam 3 bulan terakhir. Pada penilaian APGAR keluarga didapatkan 52,3\% peserta memiliki keluarga disfungsional sedang dan $43,8 \%$ sangat fungsional. Hasil penelitian menunjukkan terdapat hubungan bermakna antara fungsi keluarga dengan kualitas hidup peserta Prolanis $(p$ value $=0,014)$ sedangkan pengaruh fungsi keluarga terhadap kualitas hidup peserta Prolanis sebesar 8,8\% $(\mathrm{R} 2=0,088)$. Hal ini menjadi salah satu aspek penting bagi dokter di layanan primer agar lebih melibatkan peran fungsi keluarga dalam mengelola pasien penyakit kronis.
\end{abstract}

Kata kunci : Fungsi keluarga, kualitas hidup, pasien penyakit kronis degeneratif

\section{The Relationship Between Family Function and Quality of Life of Chronic Degeneratif Patients in Primary Health Care Service}

\begin{abstract}
Family function is one of the important factor in supporting the improvement of life quality of chronic disease patient. Having a good quality of life will reduce the risks that can make things worse. This research aimed to know the relation of family function with quality of life of chronic disease patients from the Health Social Security Organizing Agency program, that known as Prolanis BPJS in First Level Health Facilities. This analytic study used cross sectional conducted in January to February 2017 using WHO Quality of Life - BREF (WHOQOL-BREF) and Family APGAR questionnaires. The sampling technique is a total sampling of 128 Prolanis in Mitra Sehati Pratama Clinic who regularly controls in the last 3 months. APGAR Family assessment found 52.3\% of participants had a moderate family and $43.8 \%$ were very functional. The result showed that there was a significant correlation between family function and quality of life of Prolanis participants ( $p$ value $=0.014$ ) while the influence of family function on quality of life of Prolanis participants was $8.8 \%(R 2=0.088)$. This was one of the important things for primary care doctors to further involve the role of family functions in dealing with patients with chronic diseases.
\end{abstract}

Keywords : Family function, quality of life, chronic degeneratif disease patient

\author{
Korespondensi: \\ Susi Oktowaty, dr., MKM \\ Klinik Pratama Mitra Sehati \\ Komplek Griya Mitra, Jl. Mitra Sehati Raya No. 17 Cinunuk Kab. Bandung \\ Mobile : 081322829893 \\ Email : ytawotkoisus@yahoo.com
}




\section{Pendahuluan}

Perhatian dunia terhadap penyakit tidak menular (PTM) semakin meningkat karena semakin meningkat pula frekuensi kejadiannya pada masyarakat di berbagai negara. Data dari World Health Organization (WHO) tahun 2008 menunjukkan bahwa penyebab utama kematian di Asia Tenggara adalah penyakit kronis degeneratif, yaitu sebanyak 55\%. Meningkatnya prevalensi penyakit degeneratif tidak saja berkaitan dengan meningkatnya morbiditas, mortalitas dan disabilitas di kalangan masyarakat, namun juga akan meningkatkan biaya kesehatan sehubungan dengan meningkatnya kejadian komplikasi penyakitkronis degeneratif. Untuk mengantisipasi terjadinya peningkatan biaya kesehatan maka Badan Penyelenggara Jaminan Sosial (BPJS) Kesehatan meluncurkan Program Pengelolaan Penyakit Kronis yang disebut dengan Prolanis. Prolanis adalah sebuah program dengan sistem pelayanan kesehatan dan pendekatan proaktif yang dilaksanakan pada Fasilitas Kesehatan Tingkat Pertama (FKTP) secara terintegrasi dengan tujuan agar tercapai kualitas hidup yang optimal dengan biaya pelayanan kesehatan yang efektif dan efisien. Dengan tercapainya kualitas hidup optimal diharapkan komplikasi penyakit dapat dicegah.

Kualitas hidup adalah persepsi individu mengenai posisi mereka dalam kehidupan sesuai dengan konteks budaya dan sistem nilai dimana mereka hidup, serta dalam hubungannya dengan harapan, tujuan, standar yang ditetapkan oleh individu tersebut. Instrumen penilaian kualitas hidup yang digunakan pada penelitian ini dikembangkan oleh sekelompok ahli dari WHO (2004) yaitu The World Health Organization Quality of Life (WHOQOL) - BREF yang telah diterjemahkan dalam Bahasa Indonesia dan dilakukan tes validasi. Penilaian terdiri dari empat dimensi, yaitu kondisi fisik, psikologis, hubungan sosial dan lingkungan individu. Hasil penjumlahan dari semua nilai pertanyaan dikelompokkan dalam kategori kualitas hidup baik dan yang kurang dalam kategori kualitas hidup kurang. Kualitas hidup tidak semata-mata didapat dengan sendirinya, namun merupakan peran dari berbagai faktor diantaranya adalah keluarga. ${ }^{1,2}$ Penelitian oleh Kang dkk di China dengan menggunakan instrumen WHOQOL BREF dapat membuktikan bahwa dukungan keluarga dalam konteks hubungan sosial adalah salah satu faktor yang dapat memengaruhi kualitas kesehatan pasien kronis termasuk diabetes melitus. ${ }^{3}$

Mengingat pentingnya peran keluarga khususnya dalam meningkatkan kualitas hidup masyarakat maka pemerintah telah mencanangkan Peraturan Menteri Kesehatan Republik Indonesia Nomor 39 Tahun 2016 tentang Pedoman Penyelenggaraan Program Indonesia Sehat Dengan Pendekatan Keluarga. Pedoman ini dimaksudkan untuk meningkatkan derajat kesehatan melalui upaya kesehatan dan pemberdayaan masyarakat dengan dukungan finansial dan pemerataan pelayanan kesehatan yang merupakan prioritas pembangunan kesehatan pada periode 2015-2019.

Keluarga mempunyai peran yang sangat penting dalam mengembangkan, mencegah, mengadaptasi dan atau memperbaiki masalah kesehatan yang ditemukan dalam keluarga itu sendiri. Masalah kesehatan dalam keluarga saling berkaitan dan saling memengaruhi antar anggota keluarga yang pada akhirnya akan memengaruhi masyarakat yang ada disekitarnya. Oleh karena itu keluarga mempunyai posisi yang strategis untuk dijadikan sebagai bagian dari unit pelayanan kesehatan.,

Keluarga yang fungsional merupakan salah satu faktor pendukung penting bagi keluarga dalam memecahkan masalah kesehatan serta meningkatkan kualitas hidup anggota keluarga yang sakit. $^{3}$ Instrumen penilaian terhadap fungsi keluarga yang digunakan adalah APGAR Keluarga (Family APGAR), yaitu penilaian fungsi internal keluarga ditinjau dari hubungan setiap anggota keluarga terhadap anggota keluarga lainnya yang diciptakan oleh Smilkstein pada Tahun 1978.

Penilaian berdasarkan kepuasan hubungan dalam keluarga ditinjau dari aspek Adaptation (adaptasi), Partnership (kemitraan), Growth (pertumbuhan), Affection (kasih sayang) dan Resolve (kebersamaan).

Pada aspek adaptasi menilai kemampuan keluarga untuk menggunakan dan membagi sumber daya yang dimiliki oleh setiap anggota keluarganya. Aspek kemitraan menilai kemampuan dalam berbagi, membuat keputusan dan memecahkan masalah bersama melalui komunikasi yang baik. Aspek pertumbuhan menilai tingkat kepuasan anggota keluarga dalam hal kebebasan untuk mencapai perubahan atau pertumbuhan baik fisik maupun mental. Pada aspek kasih sayang yang dinilai adalah kepuasan anggota keluarga terhadap keintiman dan reaksi emosional diantara anggota keluarga. Aspek kebersamaan mewakili bagaimana waktu, ruang dan keuangan yang dibagikan. Hal ini mengukur kepuasan anggota keluarga dengan komitmen yang dibuat oleh anggota keluarga tersebut. ${ }^{6}$

Hasil jawaban yang terkumpul dari 5 skor APGAR keluarga dijumlahkan dan dikelompokan dalam 3 kategori, yaitu disfungsional berat atau 
fungsi keluarga tidak sehat, disfungsional sedang atau fungsi keluarga kurang sehat serta sangat fungsional atau fungsi keluarga sehat.

Penilaian APGAR Keluarga lebih menggambarkan hubungan internal individu langsung kepada seluruh anggota keluarganya. Bila terdapat masalah dalam keluarga, bagaimana sikap dan komunikasi antar anggota keluarga untuk menyelesaikan masalah. Bagaimana kebersamaan, kasih sayang dan rasa saling menunjang satu sama lain. Hal-hal tersebut membantu menumbuhkan kualitas hidup individu. Hal ini sejalan dengan penelitian Takenaka di Jepang yang menyatakan bahwa penilaian APGAR Keluarga terutama untuk mengetahui bagaimana sebuah keluarga membangun rasa kebersamaan yang penting dalam membangun keluarga yang fungsional. Keluarga yang fungsional merupakan salah satu terapi potensial dalam mengatasi masalah keluarga. Dokter di layanan primer sebaiknya memperhatikan fungsi keluarga pasien melalui penilaian APGAR Keluarga, dengan demikian dokter dapat mengintervensi keluarga untuk menunjang terapi. ${ }^{4}$

Sejak tahun 2011 Corales dan Medina dari Filipina telah mengembangkan sebuah instrumen untuk menilai fungsi keluarga yang memiliki anak dengan penyakit kanker, yaitu modifikasi kuesioner APGAR Keluarga untuk melihat faktor yang berasal dari internal dan kuesioner SCREEM (Social, Culture, Religion, Economy, Education, Medical) untuk mencari faktor dari eksternal. Instrumen tersebut dinamakan SCREEMRES. Penilaian fungsi keluarga tersebut sangat dibutuhkan untuk lebih mengoptimalkan kolaborasi dengan keluarga dalam pengelolaan pasien kanker yang lebih baik. ${ }^{5}$

Tujuan yang ingin dicapai pada penelitian ini adalah menganalisis hubungan antara fungsi keluarga dengan kualitas hidup serta mengetahui seberapa besar pengaruh fungsi keluarga yang diukur melalui APGAR keluarga terhadap kualitas hidup pasien penyakit kronis peserta BPJS di Fasilitas Kesehatan Tingkat Pertama.

\section{Metode}

Metode penelitian adalah analitik kuantitatif dengan pendekatan potong lintang dengan menggunakan kuesioner WHOQOL-BREF dan APGAR keluarga yang telah divalidasi. Penelitian dilakukan di Klinik Pratama Mitra Sehati pada bulan Januari dan Februari 2017. Subjek penelitian adalah peserta Prolanis BPJS Kesehatan di Klinik Pratama Mitra Sehati, yang terdiri dari penyandang hipertensi, diabetes melitus dan asma bronchiale. Dari 240 peserta
Prolanis yang terdaftar, hanya 150 peserta yang memenuhi kriteria inklusi penelitian yaitu bersedia menjadi responden, terdaftar aktif di Klinik Pratama Mitra Sehati minimal 6 bulan sebelum penelitian berlangsung serta kontrol rutin ke dokter setiap bulan selama 3 bulan berturut-turut yaitu Oktober, November dan Desember 2016. Kriteria eksklusi subjek penelitian adalah peserta yang tidak bersedia mengisi kuesioner atau tidak mengisi kuesioner dengan lengkap. Penelitian ini terdiri dari 2 variabel, yaitu variabel terikat (dependen) yaitu kualitas hidup peserta Prolanis menggunakan instrumen WHOQOLBREF serta variabel bebas (independen) yaitu fungsi keluarga peserta Prolanis di Klinik Mitra Sehati menggunakan instrumen APGAR keluarga. Metode statistik yang digunakan adalah analisis univariat untuk melihat distribusi frekwensi masing-masing variabel serta analisis bivariat dengan uji chi square untuk menganalisis hubungan antara variabel independen dan dependen. Analisis multivariat dilakukan dengan menggunakan regresi logistik untuk melihat pengaruh antara variabel independen dengan dependen dan koefisien determinasi $(R 2)$ untuk mengetahui seberapa besar kemampuan variabel independen untuk berkontribusi terhadap variabel dependen dalam satuan persentase.

Etika penelitian telah didapat melalui prosedur kaji etik dan mendapat pernyataan disetujui pelaksanaannya dari Komisi Etik Penelitian dan Kesehatan Fakultas Kedokteran Universitas Padjadjaran Bandung, dengan Surat Keterangan Persetujuan Etik Nomor: 89/ UN6C1.3.2/KEPK/ $\mathrm{PN} / 2017$.

\section{Hasil}

Dari total sample 150 responden peserta Prolanis yang terdaftar di Klinik Pratama Mitra Sehati, hanya 128 responden berhasil mengisi dan mengembalikan kuesioner. Jumlah sampel tersebut sudah melampaui batas sampel minimal (108) berdasarkan Tabel Krejcie.

Gambaran karakteristik sampel menunjukkan jumlah responden lebih banyak pada usia lebih dari 60 tahun (52\%), jenis kelamin perempuan 76 $(59,4 \%)$, status sudah menikah $(82 \%)$, domisili tinggal di rumah sendiri (84.4\%), tinggal serumah dengan keluarga lengkap (59\%), mengalami pendidikan setingkat SMU atau lebih (77\%), tinggal di rumah sendiri sebanyak $(59,4 \%)$, mempunyai penghasilan sendiri $(59,4 \%)$ serta peserta Prolanis penyandang hipertensi $(62,5 \%)$. Pada tabel 2 diperlihatkan hasil perhitungan WHOQOL-BREF yang sudah ditransformasikan sesuai ketentuan diperoleh nilai rata-rata sebesar 
209, maka nilai > 209 masuk dalam kategori individu yang mempunyai kualitas hidup baik. Pada penelitian ini didapat $52,3 \%$ responden memiliki kualitas hidup baik. Distribusi fungsi keluarga hasil perhitungan APGAR Keluarga sebagian besar memiliki disfungsional sedang $(52,3 \%)$.

Tabel 1 Distribusi Frekuensi Karakteristik Responden

\begin{tabular}{lc}
\hline Karakteristik (n=128) & Jumlah \\
\hline Usia & \\
$<60$ tahun & $66(52 \%)$ \\
$>=60$ tahun & $62(48 \%)$ \\
Jenis Kelamin & \\
Laki-laki & $52(40,6 \%)$ \\
Perempuan & $76(59,4 \%)$ \\
Status Pernikahan & \\
Menikah & $105(82 \%)$ \\
Janda/ Duda/ Belum & $23(18 \%)$ \\
menikah & \\
Tinggal Serumah & \\
Keluarga Lengkap & $75(59 \%)$ \\
Keluarga Tidak Lengkap & $53(41 \%)$ \\
Domisili: & \\
Bukan Rumah & \\
Sendiri & \\
Rumah Sendiri & \\
Pendidikan & \\
Rendah & \\
Tinggi & \\
Penghasilan & \\
Tidak Berpenghasilan & \\
Berpenghasilan & \\
\hline Karakteristik (n=128) & \\
PROLANis & \\
Diabetes Melitus & \\
\hline
\end{tabular}

Pada tabel 3 menjelaskan hubungan antara fungsi keluarga APGAR Keluarga dengan kualitas hidup WHOQOL-BREF menggunakan uji statistika Chi-Square diperoleh informasi dimana nilai $p$ lebih kecil dari 0,05 (nilai $p<0,014$ ) yang berarti signifikan atau bermakna secara statistik. Pada kualitas hidup kurang, nilai APGAR Keluarga yang terbanyak adalah disfungsional sedang, yaitu sebanyak 38 atau $62,3 \%$. Pada kelompok kualitas hidup baik sebagian besar memiliki APGAR Keluarga sangat fungsional, yaitu 37 atau sebesar $55,3 \%$.

Pada analisis multivariat terlihat pengukuran fungsi keluarga yang diukur dengan instrumen APGAR Keluarga mempunyai pengaruh pada kualitas hidup sebesar 0,088 atau $8,8 \%$.

Tabel 2 Distribusi Frekuensi Pengukuran Variabel

\begin{tabular}{lc}
\hline \multicolumn{1}{c}{ Variabel } & Jumlah \\
\hline WHOQOL-BREF & \\
Kurang & $61(47,7 \%)$ \\
Baik & $67(52,3 \%)$ \\
APGAR Keluarga & \\
$\quad$ Disfungsional Berat & $5(3,9 \%)$ \\
Disfungsional Sedang & $67(52,3 \%)$ \\
Sangat Fungsional & $56(43,8 \%)$ \\
\hline
\end{tabular}

Tabel 3 Hubungan antara Fungsi Keluarga (APGAR Keluarga) terhadap Kualitas Hidup (WHOQOL BREF)

\begin{tabular}{lccc}
\hline \multirow{2}{*}{ Variabel } & \multicolumn{2}{c}{ Kualitas Hidup } & \multirow{p}{p}{} \\
\cline { 2 - 3 } & Kurang & Baik & value \\
\hline APGAR Keluarga & & & \\
Disfungsional & 4 & 1 & \\
Berat & $(6,6 \%)$ & $(1,5 \%)$ & \\
Disfungsional & 38 & 29 & 0,014 \\
Sedang & $(62,3 \%)$ & $(43,3 \%)$ & \\
Sangat Fungsional & 19 & 37 & \\
& $(31,1 \%)$ & $(55,3 \%)$ & \\
\hline
\end{tabular}

\section{Pembahasan}

Pada penelitian ini responden yang mempunyai kualitas hidup sebagian besar memiliki fungsi keluarga yang sangat baik. Hal ini memperlihatkan adanya hubungan bermakna antara fungsi keluarga dengan kualitas hidup, baik dari aspek kesehatan fisik, psikologis, hubungan sosial dan lingkungan. Hubungan sosial meliputi hubungan personal dan dukungan sosial termasuk dukungan keluarga menjadi salah satu aspek penting dalam membangun kualitas hidup. Hasil penelitian Anikha pada Tahun 2015 di sebuah rumah sakit di Surabaya bahwa terdapat pengaruh dari dukungan keluarga terhadap kualitas hidup pasien disamping pengaruh status diabetes pada pasien penyakit 
ginjal kronis dengan hemodialisis itu sendiri. Hal ini memperlihatkan bahwa pentingnya intervensi keluarga pada pengelolaan pasien penyakit ginjal kronis dengan hemodialisis. ${ }^{7}$ Begitu juga pada penelitian Arianti yang menemukan adanya hubungan antara dukungan sosial dan kualitas hidup pada lansia penderita hipertensi di Bandung. Diperoleh data bahwa kelompok lansia hipertensi dalam penelitian ini cenderung akan terdorong untuk berupaya menjalani pengobatan dengan baik dan mencapai kualitas hidup yang tinggi ketika merasa memiliki dukungan sosial yang tinggi, khususnya ketika dukungan keluarga dinilai positif untuk membantunya. ${ }^{8}$

Responden pada penelitian ini sebagian besar tinggal di rumah sendiri beserta keluarga inti, yaitu anak dan cucunya. Dengan demikian peran keluarga sangat besar dirasakan oleh para responden dalam menjalankan kehidupan sehariharinya. Dukungan keluarga merupakan salah satu unsur penting dalam membangun fungsi keluarga pada penilaian APGAR Keluarga. Hasil analisis menggambarkan bahwa keluarga fungsional cenderung mempunyai kualitas hidup lebih baik terutama dari aspek hubungan sosial termasuk dukungan keluarga, sebaliknya keluarga tidak fungsional cenderung memiliki kualitas hidup yang kurang. Hasil penelitian Rosland, Heiser, dkk di Michigan Tahun 2010 mengatakan bahwa terdapat pengaruh antara fungsi keluarga dengan kemandirian pasien diabetes dan penyakit jantung. Fungsi keluarga yang tinggi berkaitan dengan tingkat dukungan keluarga yang lebih tinggi pula. Semakin tinggi fungsi keluarga semakin baik kemandirian pasien, dengan demikian kualitas pasien akan semakin baik pula. ${ }^{9}$ Berbeda dengan penelitian Dwi Handayani pada lansia yang mengikuti Posbindu (Pos pembinaan terpadu) di Surakarta. Hasil penelitian menunjukkan dukungan keluarga tidak ada hubungannya dengan kepatuhan lansia untuk mengikuti Posbindu. Kepatuhan untuk mengikuti kegiatan Posbindu adalah salah satu bentuk upaya meningkatkan kualitas hidup dari sisi fisik. Semakin baik persepsi seseorang terhadap kesehatan fisiknya maka akan semakin baik pula kualitas hidupnya. ${ }^{10}$

Pada penelitian ini sebagian besar responden masih berusia dibawah 60 tahun, berpendidikan minimal SMA dan sudah tidak aktif bekerja di luar rumah, namun masih dapat mengurus dirinya sendir dalam aktifitas sehari-hari. Hasil analisis menunjukkan bahwa selain fungsi keluarga yang terukur oleh APGAR Keluarga, masih ada faktor lain yang dapat meningkatkan kualitas hidup pasien kronis, diantaranya adalah kemandirian pasien dalam perawatan atau pemeliharaan kesehatan diri (self-care). Kemandirian dapat dibangun oleh beberapa faktor, diantaranya usia, kekuatan dan kesehatan fisik, adanya motivasi dan keinginan untuk bertindak. Hal ini pernah dibuktikan pada penelitian Kusniyah, Nusiswa dan Rahayu terhadap pasien diabetes. Semakin tinggi self care atau kemandirian pasien diabetes maka semakin baik tingkat HbA1C, dengan demikian semakin baik pula kualitas hidup pasien. ${ }^{11}$

Peran dokter di layanan primer serta petugas medis di faskes primer sangat penting dalam membantu menumbuhkan rasa percaya diri sehingga pasien dapat lebih mandiri mengatasi masalah kesehatan pasien. Salah satunya adalah berkolaborasi dan bekerjasama dengan keluarga atau pendamping pasien. Tujuannya untuk meningkatkan dukungan keluarga terhadap pengelolaan pasien. Pada penelitian Fuji di Jawa Barat menyatakan bahwa dukungan keluarga mempunyai pengaruh positif terhadap kualitas hidup pasien diabetes khususnya dalam bentuk dorongan (encouragement) dari keluarga. Dengan demikian fungsi keluarga akan bertambah baik dan kualitas hidup pasienpun meningkat. ${ }^{12}$ Hasil penelitian Elyasari di Lampung juga menyatakan adanya hubungan antara dukungan keluarga dengan keaktifan pasien diabetes melitus dalam melakukan kontrol pemeriksaan gula darah. ${ }^{13}$ Intervensi keluarga terutama perilaku keluarga yang mendukung proses penyembuhan pasien. Dalam hal ini pengaruh psikososial dari keluarga lebih berpengaruh pada pengontrolan gula darah pasien dibandingkan hanya sekedar minum obat teratur. Hal ini dikemukakan dalam penelitian Keogh dkk. ${ }^{14}$ Pada penelitian Kim dan Given dari American Cancer Society menemukan adanya efek yang memengaruhi kualitas keluarga pasien penyakit kronis terutama kanker. Bukan hanya psikologis, namun juga fisik, spiritual dan perilaku yang disesuaikan dengan kondisi pasien penyakit kronis. ${ }^{15} \mathrm{Hal}$ serupa juga dikemukakan oleh Golics dari hasil penelitiannya tentang kualitas hidup keluarga pasien penyakit kronis akibat pengaruh dari anggota keluarga yang menderita penyakit kronis, antara lain dampak pada emosional, aktivitas keseharian, hubungan keluarga bahkan kesehatan keluarga. ${ }^{16}$ Penelitian ini mempunyai beberapa keterbatasan diantaranya adalah pemahaman kalimat pada kuesioner WHOQOLBREF yang telah diterjemahkan ke dalam bahasa Indonesia dan sudah divalidasi. Beberapa responden perlu didampingi dalam pengisian, terutama pada yang usianya sudah lanjut atau pada beberapa responden yang berpendidikan rendah. Peneliti harus menyediakan waktu untuk menjelaskan pertanyaan responden, sementara waktu penelitian terbatas.

Simpulan, pasien penyakit kronis degeneratif 
yang termasuk dalam kelompok Prolanis pada penelitian ini lebih banyak yang memiliki kualitas hidup baik serta memiliki keluarga yang sangat fungsional, sehingga dapat dikatakan terdapat hubungan antara fungsi keluarga dengan kualitas hidup pada pasien penyakit kronis degeneratif. Pengaruh fungsi keluarga terhadap kualitas hidup pasien penting untuk diperhatikan oleh dokter di layanan primer dalam mengelola pasien dengan penyakit kronis degeneratif tersebut. Penilaian kualitas hidup pasien yang biasa dilakukan dokter di tempat praktik kebanyakan hanya pemeriksaan fisik saja. Diharapkan penelitian ini dapat mendorong dokter di layanan primer untuk membuat penilaian kualitas hidup pasien melalui aspek lainnya seperti aspek psikologis, hubungan social serta lingkungan individunya. Kualitas hidup pasien secara menyeluruh baik lahir maupun bathin diharapkan akan menghindari kemungkinan bertambah parahnya penyakit atau komplikasi. Penilaian fungsi keluarga dan kualitas pasien sebaiknya menjadi bagian dari pemeriksaan rutin pada setiap pasien penyakit kronis degeneratif dan dimasukkan dalam rekam medis Dokter Layanan Primer.

\section{Daftar Putaka}

1. World Health Organization, WHOQOLBREF, Introduction, Administration, Scoring And Generic Version of The Assessment. 1996

2. Azizah, Sofyan A., Suyanto. Gambaran Kualitas Hidup Pasien Kanker Serviks Yang Menjalani Radioterapi Di RSUD Arifin Achmad Provinsi Riau Periode 2011 2013. Jurnal Online Mahasiswa Universitas Riau, Vol. 1, No 2. Riau. 2014 (diunduh 20 Desember 2016). Tersedia dari:https://jom. unri.ac.id/index.php/JOMFDOK/article/ view/3173

3. Kang CM, Chang SC, Chen PL, Liu PF, Liu WC, Chang CC et al. Comparison of family partnership intervention care vs. conventional care in adult patients with poorly controlled type 2 diabetes in a community hospital: A randomized controlled trial. International Journal of Nursing Studies.2010; 1363-1373.

4. Takenaka H. Ban.N. The Most Important Question In Family Approach: The Potential Of The Resolve Item Of The Family APGAR In Family Medicine. Asia Pac Fam Medi. 2016.

5. Corales A.T.P, Medina M.F. Family Resouces Study: Part 1: Family Resources, Family Function and Caregiver Strain in Childhood Cancer. Philipine; Asia Pac Fam Medi. 2011.
6. Leopando ZE, Alip BAJ, Bernandez TL, Hipol CL, Maglonzo, Olazo, Samaniego, Tinio. Text Book of Family Medicine Volume 1. Philipine. 2014: 58-90.

7. Anikha Widya Bestari. Influence Of Family Support And DM Status With Hemodialysis Patient's Quality Of Life. E-journal.unair. Vol 4, No 2 (2016).

8. Arianti K., Hubungan Antara Dukungan Sosial Dan Kualitas Hidup Pada Lansia Penderita Hipertensi. Diploma Thesis. Universitas Padjadjaran. Bandung, 2011.

9. Rosland A.M., Heisier M., ed all. Family Influences on Self-Management Among Functionally Independent Adults with Diabetes or Heart Failure: Do Family Members Hinder As Much As They Help?. NIH Public Access. Michigan. 2010.

10. Handayani D., Wahyuni, Hubungan Dukungan Keluarga Dengan Kepatuhan Lansia Dalam Mengikuti Lansia Di Posyandu Lansia Jetis Desa Krajan Kecamatan Weru Kabupaten Sukoharjo. Jurnal Ilmu Kesehatan Gaster Surakarta. 2012; 9(1): 49-58

11. Kusniyah Y.,Nursiswati, Rahayu U. Hubungan Tingkat Self Care Dengan Tingkat HbA1C Pada Klien Diabetes Melitus Tipe 2 Di Poliklinik Endokrin RSUP DR. Hasan Sadikin. Bandung. 2016. (Diunduh 20 Januari 2016). Tersedia dari http://pustaka. unpad.ac.id/wp-content/uploads/2011/06/ hubungan_tingkat_self_care_dengan tingkat hbaīc.pdf

12. Rahmawati F, Setiawati EP., Solehati T., Pengaruh Dukungan Keluarga Terhadap Kualitas Hidup Pasien Diabetes Melitus Tipe 2. 2015. (Diunduh 20 Januari 2016). Tersedia dari http://pustaka.unpad.ac.id/wp-content/ uploads/2015/01/Artikel-Ilmiah1.pdf

13. Elyasari. Hubungan Dukungan Keluarga dengan Keaktifan Pasien Diabetes Melitus Dalam Melakukan Pemeriksaan Glukosa Darah Di RSUD Pringsewu Tahun 2014. Jurnal Keperawatan SIKes Aisyah Pringsewu. 2014.

14. Keogh K, Smith S, White P, McGilloway S, Kelly A, Gibney J, et al. Psychological Family Intervention for Poorly Controlled Type 2 Diabetes. The American Journal of Managed Care. 2011;17(2):105:13.

15. Kim Y., Given B.A. Quality of Life of Family Caregivers of Cancer Survivors. Wiley Online Library. USA. 2008.

16. Golics CJ, Khurshid M, Basra A, Salek MS, Finlay AY, The Impact of Patients' Chronic Disease on Family Quality of Life: An Experience From 26 Specialties. International Journal of General Medicine. UK.2013. 